CONF-900464--2

DE90 005449

\title{
Design of a High Power Density, Permanent Magnet, Axial Gap DC Motor
}

\author{
R. A. Hawsey, D. S. Daniel \\ Applied Technology Division \\ Oak Ridge National Laboratory \\ Oak Ridge, Tennessee 37831 \\ R. J. Thomas \\ Engineering Division \\ Oak Ridge National Laboratory \\ Oak Ridge, Tennessee 37831 \\ J. M. Bailey \\ University of Tennessee \\ Knoxville, Tennessee 37996-2110
}

\section{DISCLAIMER}

This report was prepared as an account of work sponsored by an agency of the United States Government. Neither the United States Government nor any agency thereof, nor any of their employees, makes any warranty, express or implied, or assumes any legal liability or responsibility for the accuracy, completeness, or usefulness of any information, apparatus, product, or process disclosed, or represents that its use would not infringe privately owned rights. Reference herein to any specific commercial product, process, or service by trade name, trademark, manufacturer, or otherwise does not necessarily constitute or imply its endorsement, recommendation, or favoring by the United States Government or any agency thereof. The views and opinions of authors expressed herein do not necessarily state or reflect those of the United States Government or any agency thereof.

$$
\text { BSTRIBUTIOH OF THS DOCUMENT IS UNLIMITEO }
$$

The submitted manuscript has been authored by a contractor of the U.S. Government under contract DE-AC05-84OR21400. Accordingly, the U.S. Government retains a nonexclusive, royalty-free license to publish or reproduce the published form of this contribution, or allow others to do so, for U.S. Government purposes. 


\section{DISCLAIMER}

This report was prepared as an account of work sponsored by an agency of the United States Government. Neither the United States Government nor any agency Thereof, nor any of their employees, makes any warranty, express or implied, or assumes any legal liability or responsibility for the accuracy, completeness, or usefulness of any information, apparatus, product, or process disclosed, or represents that its use would not infringe privately owned rights. Reference herein to any specific commercial product, process, or service by trade name, trademark, manufacturer, or otherwise does not necessarily constitute or imply its endorsement, recommendation, or favoring by the United States Government or any agency thereof. The views and opinions of authors expressed herein do not necessarily state or reflect those of the United States Government or any agency thereof. 


\section{DISCLAIMER}

Portions of this document may be illegible in electronic image products. Images are produced from the best available original document. 
Design of a High Power Density, Permanent Magnet, Axial Gap DC Motor

\author{
R. A. Hawsey, D. S. Daniel \\ Applied Technology Division \\ Oak Ridge National Laboratory* \\ Oak Ridge, Tennessee 37831 \\ R. J. Thomas \\ Engineering Division \\ Oak Ridge National Laboratory \\ Oak Ridge, Tennessee 37831 \\ J. M. Bailey \\ University of Tennessee \\ Knoxville, Tennessee 37996-2110
}

\begin{abstract}
In the design of drive motors for undersea vehicles, the premium placed on noise suppression suggests the use of a brush-commutated dc motor. The additional constraints of weight and volume, as well as unusual configuration, presents the axial air-gap configuration, with a permanent magnet field, as a viable candidate. In such a configuration the design of the brushes and commutator and the resulting structure becomes critical.

The report describes a novel solution to this problem. The basic motor consists of two discs containing permanent magnets on either side of a magnetic structure containing the copper windings. An advantage of this motor concept is that copper cooling may easily be accomplished through the use of liquid circulating through the stator windings.

The role of field and armature in a conventional disc motor configuration are reversed. The two discs containing the permanent magnets are rotating. The brushes are on the discs. The magnetic structure with the coils is stationary. The commutator bars are imbedded in the stationary member. Input power is supplied to the brushes through a brush-and-slip ring assembly.

An electromagnetic design analysis for a $92 \mathrm{ft}-\mathrm{lb}, 700 \mathrm{rpm}$ motor was performed. A finite element analysis has been conducted and the results show that magnetic saturation is not a limiting factor in this design. The motor torque is achievable within weight and volume constraints.
\end{abstract}

*Operated by Martin Marietta Energy Systems, Inc., for the U.S. Department of Energy under contract DE-AC05-84OR21400. 


\section{INTRODUCTION}

The brush-commutated, pancake (or disc)-shaped permanent magnetic motor has been suggested as a candidate for application in continuous duty environments. Presently, these motors are used in disc drives, for robotics, and in servo-type applications where fast acceleration time, full torque over a wide speed range, and high peak, or "burst" torque capability is required. The Applied Technology Division (ATD) staff of the Oak Ridge National Laboratory has developed a computer model of a variation of a commercial motor in order to evaluate performance.

The ATD motor assembly would consist of two motor modules; each module would be constructed of a single stator assembly with a rotor on each side of the stator. The complete motor assembly would be required to meet the following average performance specifications:

\section{Configuration}

Direct-current, brush-commutated, counterrotating output, direct drive, fully reversible, efficiency $\geq 85 \%$.

\section{Performance}

$92 \mathrm{ft}-\mathrm{lb}$ at $\pm 700 \mathrm{rpm}$ (maximum continuous)

max weight $120 \mathrm{lb}$

package size $\sim 17$-in. diam $\times 12$-in. long

operated from battery supply.

A drawing of the motor concept is shown in Fig. 1. For each module, the stator would contain the copper windings, with a total of 21 slots. Steel laminations would comprise the "teeth" but, since the flux path is closed by the back iron in each rotor, there would be no stator "yoke" required. Cooling of the stator, to remove $I^{2} R$-generated heat, is easily accomplished by coolant tubes since the stator does not rotate.

Each rotor would consist of four rare-earth permanent magnets (SmCo or NdFeB) equally spaced in front of a back iron ring. The magnets and back iron would be contained in a non-magnetic, high-performance engineering plastic such as "G-10."

'PMI Motion Technologies

49 Mall Drive

Commack, New York 11725-5703

(516) $864-1000$ 

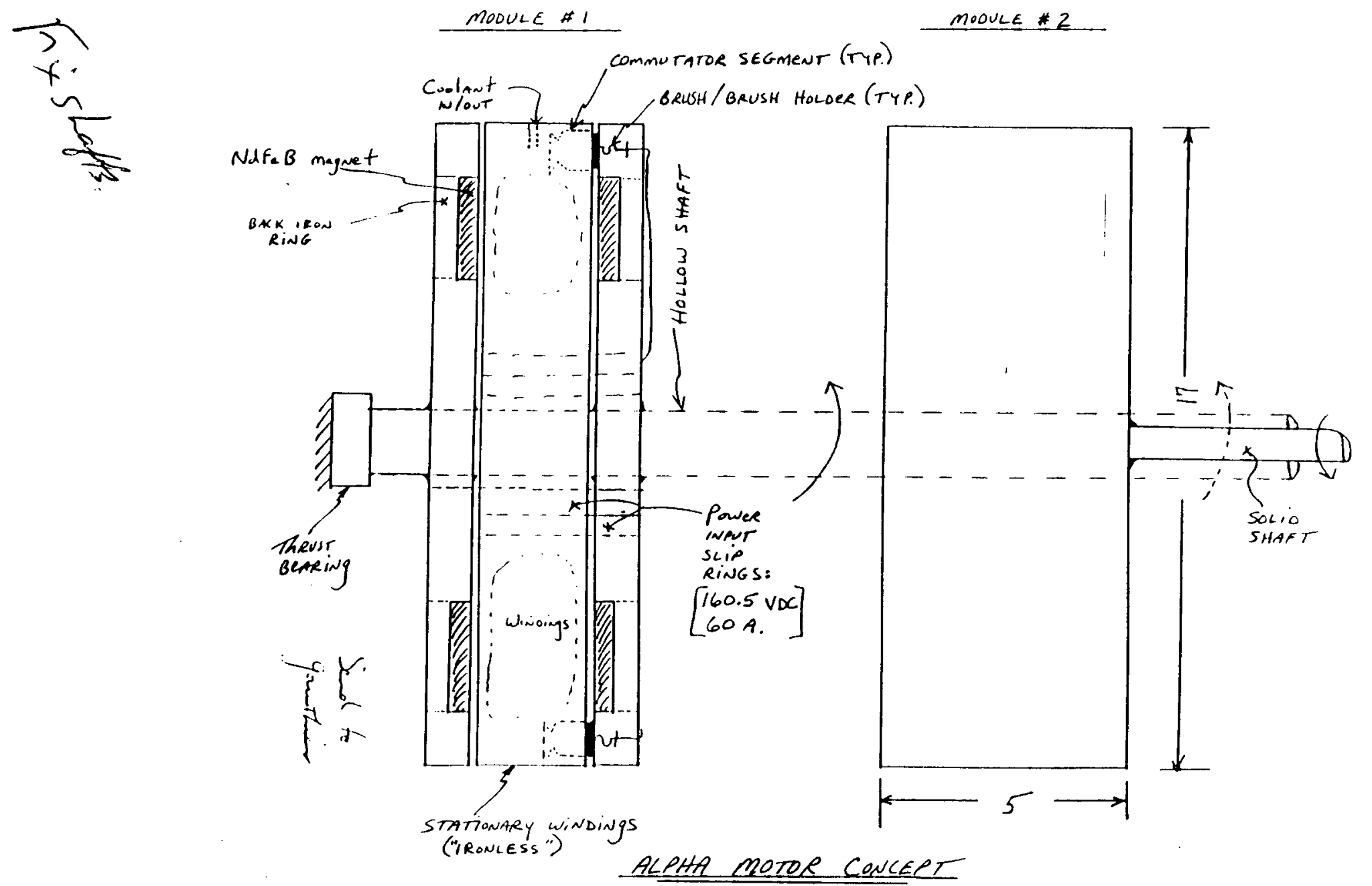

Fig. 1. ALPHA Motor Concept 
As shown in Fig. 1, one of the motor shafts would be hollow and larger in diameter than the other for counterrotation of each shaft.

Electric power would be transferred from the voltage-controlled source to the stator windings via two sets of brushes and one slip ring assembly. The first set of brushes and slip rings is needed to energize the brushes in contact with the commutator bars. The second set of brushes, also located on the rotor, would provide dc current to the commutator bars located on the stator. At full torque and rated speed, the motor will draw $\sim 60$ amperes at 161.5 VDC.

\section{Design Parameters}

Since the speed of the motor is relatively low, it was decided to use a wave winding in the two stators. With this decision, a four-pole motor with 21 slots and 21 commutator segments was chosen, with a winding pitch of one in five. The steady-state equivalent circuit of a separately excited dc motor is shown in Fig. 2.

The equations are:

and

$$
\mathrm{Eg}=\mathrm{Kg} \phi \omega
$$

$$
\mathrm{Te}=\mathrm{K}_{\mathrm{T}} \phi \mathrm{la}
$$

where

$$
\begin{aligned}
& \mathrm{Eg}=\text { back emf in volts } \\
& \mathrm{Te}=\text { electrical torque in NM } \\
& \phi=\text { air gap flux in webers } \\
& \omega=\text { rotational speed in rad/s. }
\end{aligned}
$$

$K_{T}$ is the torque constant and $\mathrm{Kg}$ is the back emf constant. In the SI system of units, these two constants are equal; i.e.,

$$
K_{T}=K g=\frac{P N}{2 \pi \beta}
$$

where

$$
\begin{aligned}
& \beta=\text { parallel paths }=2 \\
& P=\text { number of poles }=4 \\
& N=\text { turns/pole }=6.25 .
\end{aligned}
$$

With a flux density of $0.8 \mathrm{~Wb} / \mathrm{m}^{2}$, the flux can be calculated as,

$$
\begin{aligned}
& \Phi=\frac{\pi}{4}\left[(14)^{2}-(8)^{2}\right] \times(0.0254)^{2} \times(0.8) \\
& \Phi=0.05 \text { weber }
\end{aligned}
$$

With 21 coils each with 25 turns (each turn consisting of 2 \#12 AWG),

$$
K_{T}=K g=\frac{4(21)(6.25)}{2 \pi(2)}=41.8
$$




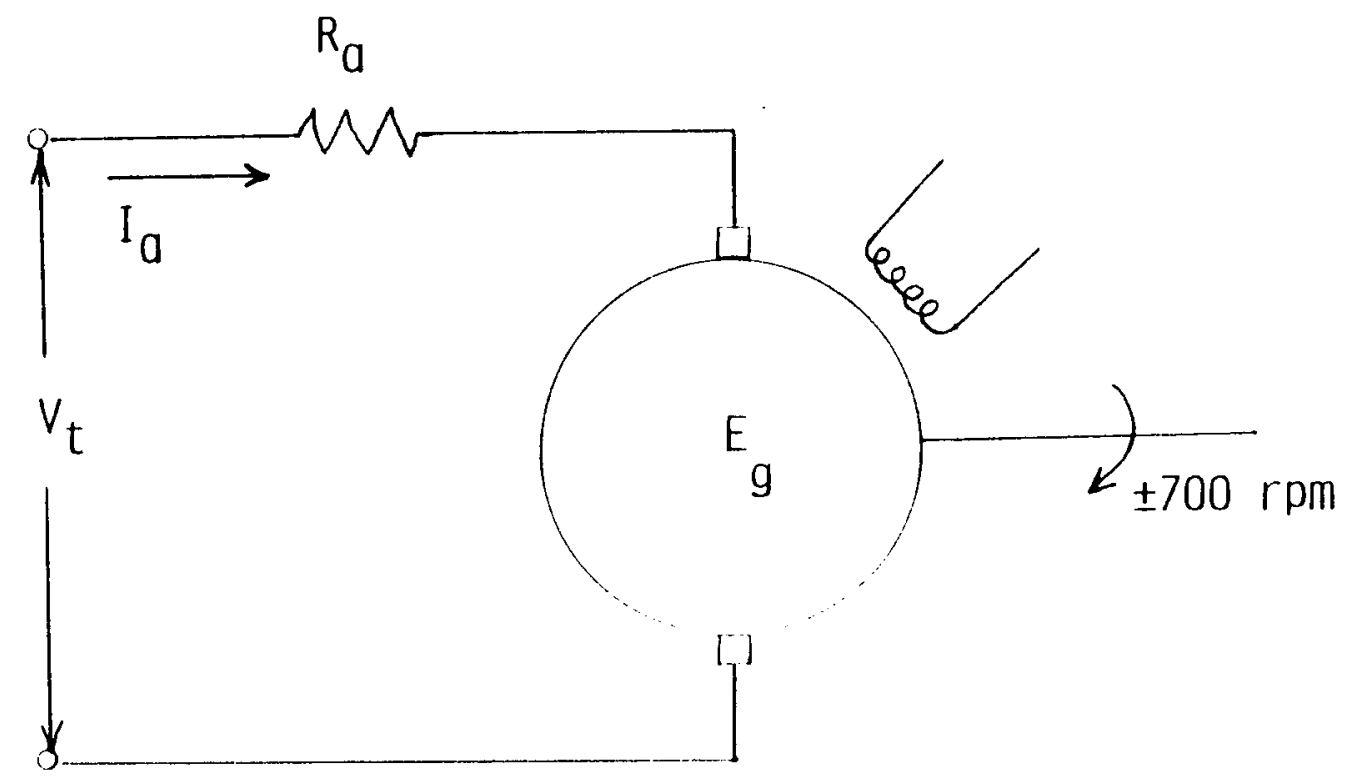

Fig. 2. Motor Equivalent Circuit 
Thus $\quad \mathrm{Te}=(41.8)(0.05)(60)$

$\mathrm{Te}=125.4 \mathrm{~N}-\mathrm{M}=92.55 \mathrm{ft}-\mathrm{lb}$

$\mathrm{Eg}=(41.8)(0.05)(73.27)=153.13$ volts.

\section{Efficiency}

For the magnetic losses, consider the stator teeth which are fabricated from tape-wound MAGNESIL - $N$ (0.007-in. thick). The available core loss curves show a core loss of 2 watts per $\mathrm{lb}$ at a frequency of $200 \mathrm{~Hz}$. For the ALPHA motor, a 4-pole motor operating at $700 \mathrm{rpm}$,

$$
\begin{aligned}
& 700=\frac{120 f}{4} \\
& \text { or } f=23.33 \mathrm{~Hz} .
\end{aligned}
$$

The teeth weigh $8.2 \mathrm{lbs}$ and scaling the frequency linearly

$$
W_{c}=\frac{23.33}{200} \times 2 \times 8.2 \cong 2 \text { watts }
$$

The back iron is made of "sawblade" steel and its B-H curve is linear. However, the flux density is a $d-c$ value and, hence, there is no core loss. (In actual operation, there may be some distortion due to the action of armature reaction but we consider this negligible.)

Each coil consists of 25 turns where each turn consists of two \#12 AWG conductors in parallel. A rough calculation shows each coil is 22.5-in. long. For standard annealed copper, resistances are related in temperature as

$$
R_{2}=R_{1} \quad \frac{234.5+t_{2}}{234.5+t_{1}}
$$

No. 12 AWG has a resistance value of $1.588 \Omega / 1000 \mathrm{ft}$. Since we utilize a wave winding, there are two parallel paths. Thus,

$$
\mathrm{Ra}=0.47 \Omega \text {. }
$$

With 30 amperes in each leg or 60 amperes total

$$
\operatorname{Pcu}=(60)^{2}(0.47)=1.7 \mathrm{~kW} \text {. }
$$

For $92 \mathrm{ft} \mathrm{lbs}$ at $700 \mathrm{rpm}$

$$
\text { eff }=\frac{9143}{9,143+1700}=84.3 \%
$$

This calculation is not exact, but assures that an efficiency of $85 \%$ should easily be obtained with more detailed design. Note that the battery must deliver at least $\mathrm{Eg}+(60 \times 0.47)=181.4 \mathrm{~V}$. for this first design. To meet a lower battery voltage configuration, the designer may use slightly bigger wire to reduce the voltage required. 


\section{Commutator/Slip Ring Design}

As previously discussed, the stator winding assembly is stationary while the permanent magnets are mounted on rotor discs. This concept presents the need for a commutator to carry D.C. armature current into the fixed coils, and also the need for slip rings to provide a means to impress current into the rotating field disc that houses the commutator brushes. A drawing of the brush/slip-ring and commutator concept is shown in Fig. 3.

Approximately 60 amperes of current will be carried by the two pairs of commutator brushes. Each brush must be capable of conducting 30 amperes, and at a nominal density of 50-60 amperes per square inch (for carbon brushes), each brush must have $1 / 2-\mathrm{sq}$ in. of contact surface. A number of slip ring brushes can be distributed around the circumference of the slip rings. If four brushes per slip ring is selected, then each brush would need to be sized for a 15 ampere current flow, or approximately 0.25 -sq in. per brush.

The commutator brush holders consist of trapezoidal slots machined perpendicular to the commutator (or air gap) into the PM disc composite. Each brush will be spring-loaded by use of a cantilever spring arrangement that will not be affected by centrifugal forces. Since total running time is short, brush wear and spring deflection (travel) should not be a problem.

The slip ring brush holders (not shown in Fig. 3) will consist of commercially available brush holders mounted to two sets of rocker arms. The rocker arm holder will be constructed to carry two positive and two negative brushes each. The holders shall be sufficiently strong to allow the power supply flexible leads to be bolted directly to the arms. The fixed mounts for the rocker arm holders will be adjustable for brush clearance to the slip rings.

The final design of the slip ring/commutator brush systems can include variations using alloys of graphite and silver, copper, or cadmium. Silver, copper, and cadmium with graphite brushes can be tried in combination with similar slip-ring and commutator materials as well as conventional carbon and brass (copper) materials. If the more exotic alloy materials are used, then the cross sectional areas of the brushes, slip rings, and commutators can be reduced. Also, spring pressures will be adjusted to meet the requirements for the type brushes being used. Commercially available brush materials and brush holders will be used where possible, as well as readily available commutator bar and slip ring material.

\section{Finite Element Analysis Model}

The ALPHA motor module has one-quarter symmetry, so a one-quarter section of the module was selected for the electromagnetic analysis. The commercial two-dimensional code MSC/MAGNETIC, version 13.1, was used for the analysis. A feature of the code is the capability to use non-linear steels.

For the analysis, the basic geometry was established by taking a section of the module at the average magnet radius of 4.63 in. and displaying the section in two dimensions. The geometry layout is shown in Fig. 4. Each rotor is modelled as 1) a permanent magnet with a specified coercivity of the magnetic flux density in $\mathrm{kA} / \mathrm{m}$; 2) a back iron ring of steel with a linear B-H curve; and 3 ) a region of air to assess whether or not the steel closes the flux path. 


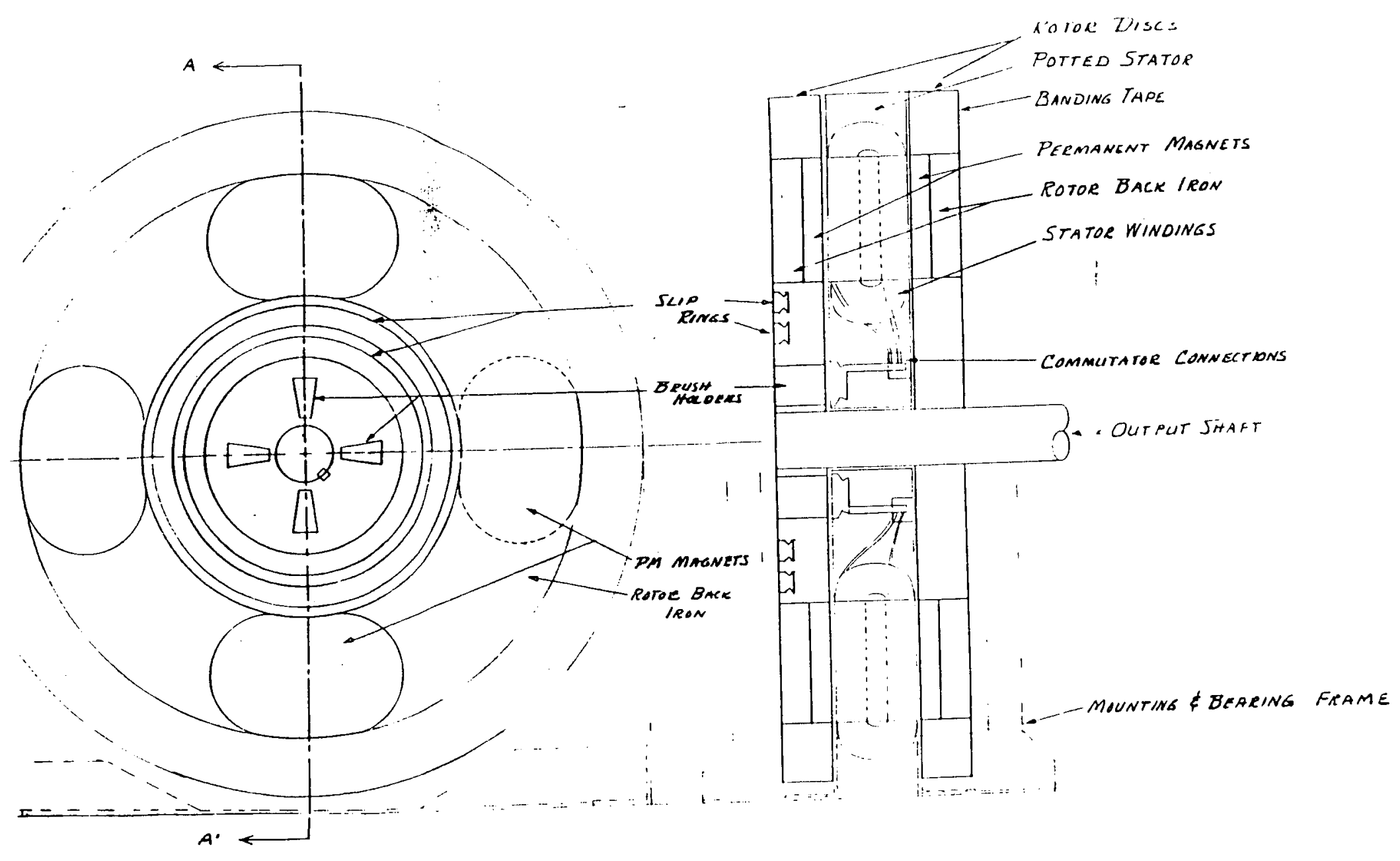

Fig. 3. Motor Geometry Showing Brush/Slip Ring Details. One Module (92 ft-lb $@ \pm 700 \mathrm{rpm}$ ). 
Fig. 4. Finite Element Geometry Layout of One Pole

Rotor


The stator is modelled with 1) "slots" consisting of air and a specified number of turns of wire and current per turn; and 2) "teeth" formed from a non-linear steel or, for some analyses, formed from a non-magnetic, non-conductive material such as engineering plastic. An adjustable physical air gap between the moving rotors and the stator was also modelled. Typical dimensions tested with the model are

\section{Axial length/inch}

$\begin{array}{lll}\text { Air (behind rotor) } & 0.25 & \\ \text { Back iron } & 0.25 & -0.50 \\ \text { Magnet } & 0.25 & \\ \text { Air gap } & 0.025 & -0.050 \\ \text { Teeth/windings } & 0.5 & -1.0\end{array}$

\section{Constraints}

The air regions on either side of the rotor back iron are constrained so that the vector potential (in webers per meter of model length) anywhere on the outside surface of the air is zero. To account for the model symmetry, the vector potential on one side of the model is constrained to be -1 times the vector potential on the other side of the model.

\section{Key Model Parameters (end turns are excluded)}

A. Dimensions

$$
\begin{array}{ll}
R_{\mathrm{av}} & =4.625 \mathrm{in} . \\
R_{1} & =3 \mathrm{in} . \\
R_{0} & =6 \mathrm{in} . \\
L & =3 \mathrm{in} . \\
\text { Circ }_{\mathrm{av}} & =7.27 \mathrm{in} . \text { for one quarter section }
\end{array}
$$

Slot width calculation $\frac{\mathrm{d}}{2}$ :

angle between the centerlines of two adjacent slots $=17.14$ degrees

for small angles, $\theta_{\text {rad }} \sim \frac{d}{R} \Rightarrow d=1.405$ in.

Therefore, $d=0.7$ in., and the tooth width is also $0.7 \mathrm{in}$.

B. Material Listing.

$$
\begin{aligned}
& \text { Material } 1=\text { air } \\
& \text { Material } 2=\text { back iron, a steel with a linear } \mathrm{B}-\mathrm{H} \text { curve } \\
& \text { Material } 3=\text { permanent magnet } \\
& \text { Material } 4=\text { silicon steel (non-linear B-H curve) }
\end{aligned}
$$

The material tables and B-H table for Material 4 is reproduced in Table 1. 
Table 1

Material Properties and B-H Table Listing

\begin{tabular}{|c|c|c|c|}
\hline $\begin{array}{l}\text { PERA } \\
\text { COYD }\end{array}$ & $\vdots$ & $\begin{array}{l}1.0000000 \\
0.00000000 E+00\end{array}$ & \\
\hline JEL & 2 & $: .0000000$ & \\
\hline TCON & 2 & $0.22000000 E-01$ & \\
\hline 405 & 1 & 0 & \\
\hline PERM & 2 & 2000.0000 & \\
\hline CONO & 2 & 5000000.0 & \\
\hline $\begin{array}{l}\text { TIEL } \\
\text { TCON }\end{array}$ & 2 & 1.0000000 & \\
\hline $\begin{array}{l}I C O N \\
4 C S\end{array}$ & 2 & 44.930000 & \\
\hline $\begin{array}{l}\text { HCS } \\
\text { PERM }\end{array}$ & 2 & 0 & \\
\hline PERM & 3 & 1.0100000 & \\
\hline CONO & 3 & $0.00000000 E+00$ & \\
\hline JIEL & 3 & 1.0000000 & \\
\hline & & $0.23237557 E-01$ & 546000.00 \\
\hline $\begin{array}{l}\text { TCON } \\
\text { TCS }\end{array}$ & 30 & $0.00000000 E+00$ & \\
\hline $\begin{array}{l}\text { MCS } \\
\text { PERM }\end{array}$ & 3 & 2000.0000 & \\
\hline CONO & 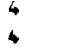 & $\begin{array}{l}2000.0000 \\
5000000.0\end{array}$ & \\
\hline PERT & 4 & 12 & \\
\hline OIEL & 4 & 1.0000000 & \\
\hline TCON & 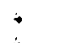 & 64.980000 & \\
\hline $\begin{array}{l}\text { MCS } \\
\text { 3HTABLE }\end{array}$ & +12 & 0 & \\
\hline $\begin{array}{l}\text { 3HTABLE } \\
0.190000005\end{array}$ & $=-02$ & 23.9788735 & $0.00000000 E+00$ \\
\hline $0.27999999 \mathrm{E}$ & $\begin{array}{l}=-0< \\
=-02 \\
=02\end{array}$ & 4.7746482 & $0.00000000 E+00$ \\
\hline $0.38000001 E$ & $=-02$ & 5.5706231 & $0.00000000 E+00$ \\
\hline $0.46999999 \mathrm{E}$ & $E-02$ & 6.3661976 & $0.00000000 E+00$ \\
\hline $0.93999999 E$ & $\begin{array}{l}E-02 \\
E-01\end{array}$ & $\begin{array}{l}7.9577670 \\
15.915696\end{array}$ & $\begin{array}{l}0.00000000 E+00 \\
0.00000000 E+00\end{array}$ \\
\hline $\begin{array}{l}0.18800000 E \\
0.56299999 E\end{array}$ & $E-01$ & $\begin{array}{l}15.915696 \\
23.873261\end{array}$ & $0.00000000 E+00$ \\
\hline 0.10310000 & & 31.830988 & $0.00000000 E+00$ \\
\hline 0.25000001 & & 39.788734 & $0.00000000 E+00$ \\
\hline 0.30000001 & & 47.766483 & $0.00000000 E+00$ \\
\hline 0.41269999 & & 55.706227 & $0.00000000 E+00$ \\
\hline 0.52499998 & & 63.661976 & $0.00000000 E+00$ \\
\hline 0.62809998 & & 71.619720 & $0.00000000 E+00$ \\
\hline 0.71269999 & & $\begin{array}{l}79.577469 \\
159.15494\end{array}$ & $\begin{array}{l}0.00000000 E+00 \\
0.00000000 E+00\end{array}$ \\
\hline $\begin{array}{l}1.2438000 \\
1.2938000\end{array}$ & & $\begin{array}{l}159.15494 \\
238.73241\end{array}$ & $0.00000000 E+00$ \\
\hline $\begin{array}{l}1.6250000 \\
1.6625000\end{array}$ & & $\begin{array}{l}318.30988 \\
397.88736\end{array}$ & $\begin{array}{l}0.00000000 E+00 \\
0.00000000 E+00\end{array}$ \\
\hline 1.5188000 & & 677.46481 & $0.00000000 E+00$ \\
\hline 1.5563000 & & 557.04230 & $0.00000000 E+00$ \\
\hline 1.5844001 & & 636.62975 & $0.00000000 E+00$ \\
\hline 1.6125000 & & 716.19120 & $0.00000000 E+00$ \\
\hline 1.6313000 & & 795.77672 & $0.00000000 E+00$ \\
\hline 1.7250000 & & 1592.5694 & $0.00000000 E+00$ \\
\hline 1.1438000 & & 2387.3242 & $0.00000000 E \nrightarrow 00$ \\
\hline 1.7625000 & & 3183.0989 & $0.00000000 E+00$ \\
\hline 1.7719002 & & 3978.8735 & $0.00000000 E+00$ \\
\hline 1.7812999 & & 6774.6486 & $0.00000000 E+00$ \\
\hline 1.7907000 & & 5570.6229 & $0.00000000 E+00$ \\
\hline 1.8001000 & & 6366.1978 & $0.00000000 E+00$ \\
\hline 1.8095000 & & 7161.9722 & $0.000000000 E+00$ \\
\hline 1.8189000 & & 7957.7471 & $0.00000000 E+00$ \\
\hline 1.8283000 & & 15915.694 & $0.00000000 E+00$ \\
\hline 1.8377000 & & 23873.260 & $0.00000000 E+00$ \\
\hline 1.8671000 & & 12830.983 & $0.00000000 E+00$ \\
\hline 1.8565000 & & 39788.736 & $0.00000000 E+00$ \\
\hline 1.8659000 & & 47746.480 & $0.00000000 E+00$ \\
\hline 1.8753000 & & 55706.230 & $0.00000000 E+00$ \\
\hline 1.8846799 & & $\$ 3661.977$ & $0.00000000 E+00$ \\
\hline 1.8941000 & & 71619.727 & $0.00000000 E+00$ \\
\hline 1.9035000 & & 79577.669 & $0.00000000 E+00$ \\
\hline 1.9129000 & & 159154.96 & $0.00000000 E+00$ \\
\hline 1.9223000 & & 238732.61 & $0.00000000 E+00$ \\
\hline 1.9317000 & & 318309.98 & $0.00000000 E+00$ \\
\hline 1.9411000 & & 397887.36 & $0.00000000 E+00$ \\
\hline 1.9505000 & & 677466.81 & $0.00000000 \varepsilon+00$ \\
\hline $\begin{array}{l}1.9599000 \\
1.9693000\end{array}$ & & $\begin{array}{l}557042.31 \\
636619.75\end{array}$ & $\begin{array}{l}0.00000000 E+00 \\
0.00000000 E+00\end{array}$ \\
\hline & & & \\
\hline
\end{tabular}


Results

The results of the finite element analysis are summarized in Fig. 5-9. Figures 5 and 7 show the flux distribution. Figure 5 is for an 0.55 in. total air gap. Figure 7 is for 1.1 in. air gap, but with 1/2-in.-thick back iron. Note that in each case, the physical distance between moving and stationary parts is 0.025 in. The thicker back iron leads to a smaller flux density. However, as stated in section 2, this flux density is not a-c and, hence, there is no core loss. Figure 6 is the flux density plot that accompanies the flux plot in Fig. 5. The important fact to note is that the flux density in the teeth is quite reasonable and seems to be less than about $1.1 \mathrm{~Wb} / \mathrm{m}^{2}$ maximum. Thus, operation at an air gap of 0.55 in. should be satisfactory. It must be emphasized that this is a 2-dimensional model and the values of flux density of 5 to 7 $\mathrm{Wb} / \mathrm{m}^{2}$ at the edges of the back iron is not a true representation of actual flux density in that material.

Referring to Fig. 9, the analysis results were plotted in the form of output torque vs current with the following variables:

Tooth material (silicon steel or air)

Total air gap distance

Magnet strength in $\mathrm{kA} / \mathrm{m}$.

The ALPHA motor torque requirement is exceeded with permanent magnet strengths of at least $640 \mathrm{kA} / \mathrm{m}$, and is significantly exceeded with the use of high-grade Samarium-Cobalt $(\mathrm{SmCo})$ magnets $(740 \mathrm{kA} / \mathrm{m})$. The use of new neodymium-iron-boron (NdFeB) magnets with $\mathrm{H}_{\mathrm{c}} \sim 900 \mathrm{kA} / \mathrm{m}$ would increase this torque an additional amount without saturating the silicon steel teeth. The rotor operating temperature would be limited to $\leq 150^{\circ} \mathrm{C}$ with the NdFeB magnets or $\leq 350^{\circ} \mathrm{C}$ with the SmCo magnets, but the limitations of other materials (rotor housing, bearing temperatures, winding insulation) would be a limiting factor at lower temperatures than these. There is an offset in the torque vs current plot with magnetic material in Fig. 9. For the plot where there is no magnetic steel, the offset does not appear. Since we were limited by economic and time constraints, the number of finite elements have been minimized, and we feel that increasing the finite elements would alleviate this problem. However, the magnitude of this offset only ranges from 8 to $12 \mathrm{tt}-1 \mathrm{~b}$, and, hence, we proceeded with the minimum element set.

The fact that the model predicts an excess of steady-state torque capability is fortunate since motor weight estimates (see next section) will require that the machine diameter be decreased slightly to meet the weight goal.

The analysis shows that the machine radius may be decreased by up to $20 \%$, with a corresponding decrease in motor weight, and still meet the ALPHA requirement. Another option available to the designer would be to reduce the current by up to $20 \%$ with a reduction of more than $20 \%$ in the $I^{2} R$ loss and subsequent cooling system requirements.

Another option available to the designer is the removal of all magnetic material from the stator. As shown in Fig. 9, the resulting motor torque would only be $70 \%$ of the torque achieved with steel present in the stator. However, the use of high- $\mathrm{H}_{c} \mathrm{NdFeB}$ magnets would be expected to result in torque approaching $90 \%$ of the ALPHA requirement. In addition, removal of all steel would permit the addition of more ampere-turns, and, hence, increase the torque. 
LECTDF POTEHTIHL (LEEERS I1!

IAFIITH $=$ B.4321E-B1

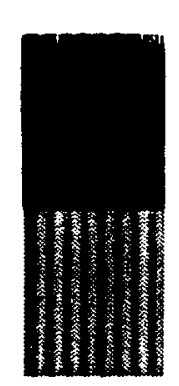

日. $4321 E-01$

0. $.3717 E-61$

日. $3114 E-61$

$0.2515 E-51$

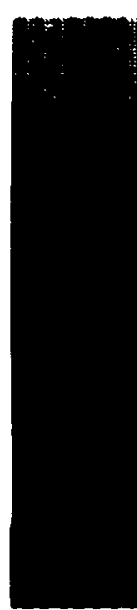

0. $1 \mathrm{9TE-G1}$

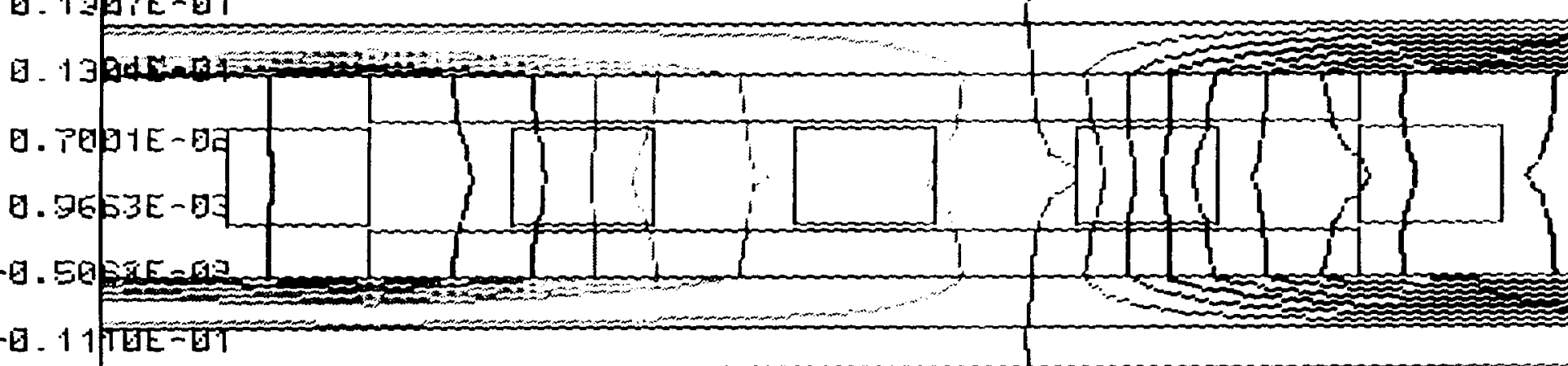

$-0.1714 E-61$

$-0.2317 E-01$

$-6.2321 E-911$

- $9.3524 E-51$

HIHIHUH $1=$-日.35ट4E-日1

Fig. 5. Flux Pattern Produced With +31 Amperes and 0.55 in. Total Air Gap. 


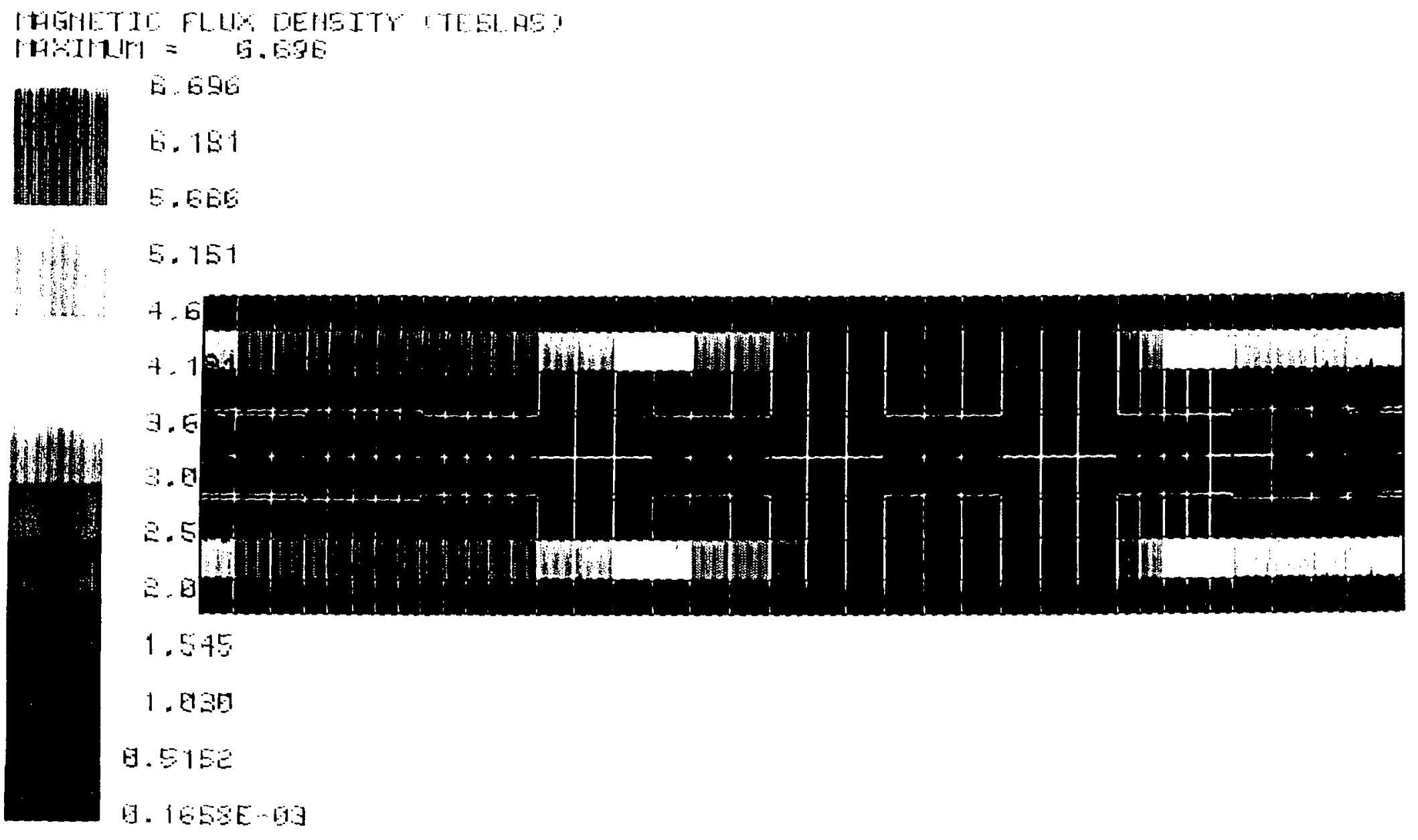

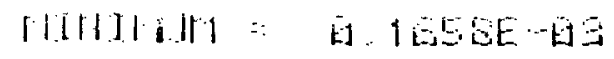

Fig. 6. Flux Density for +31 Amperes, 0.55 in. 'T'otal Air Gap. 


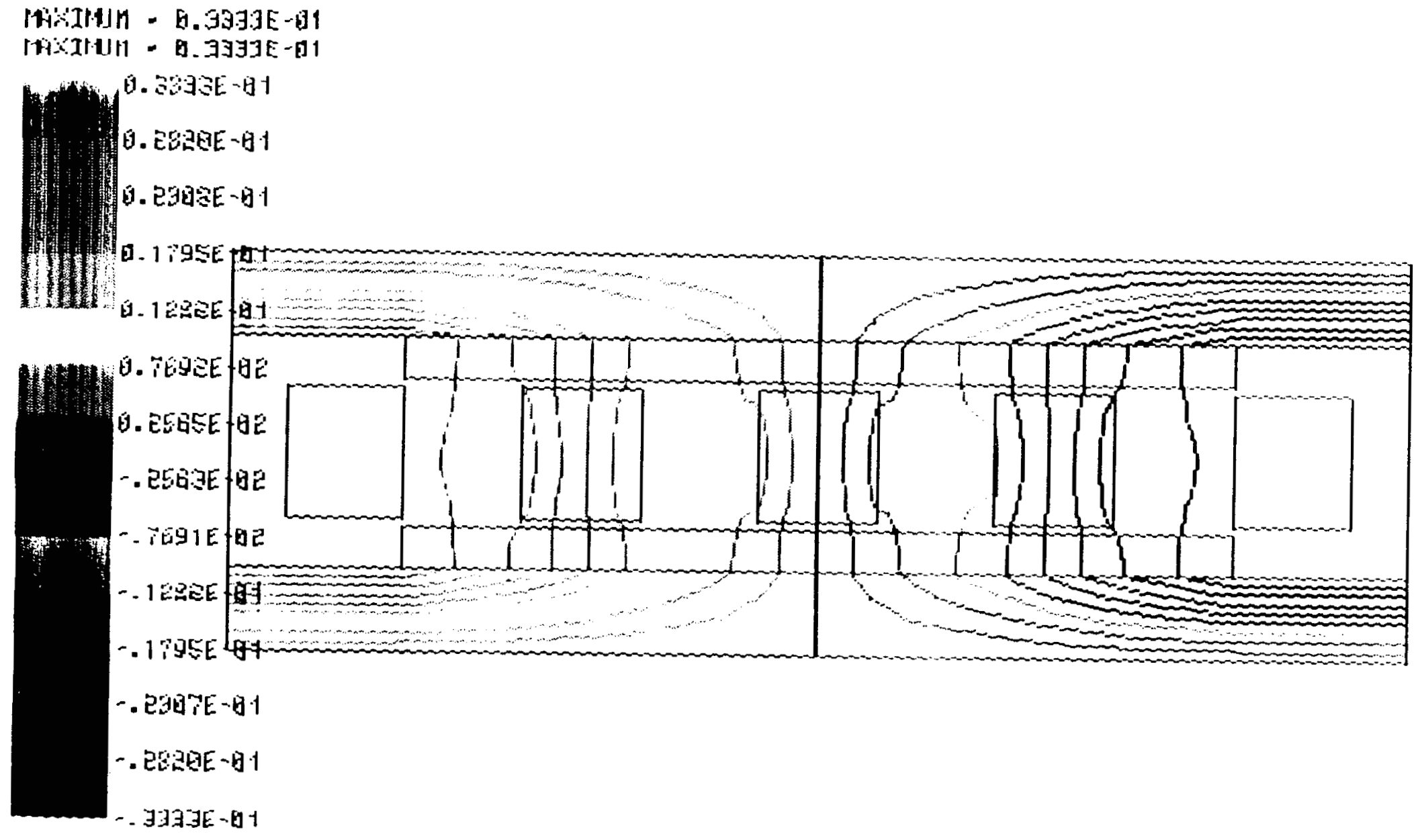

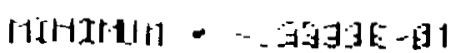

Fig. 7. Flux Distribution for 1.10 in. Total Air Gap and $1 / 2$ in. Back Iron Thickness. 


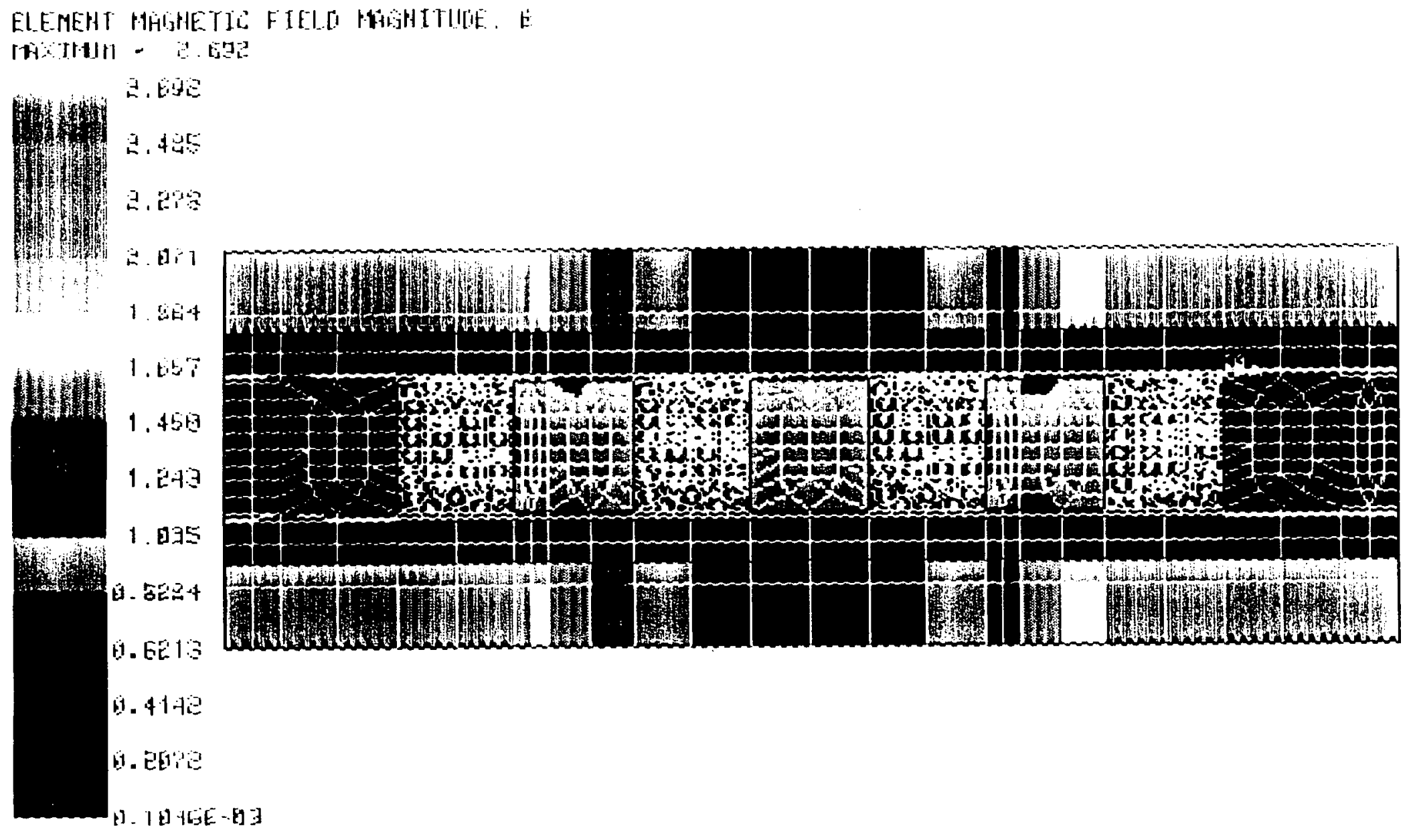

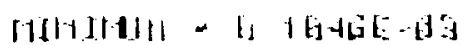




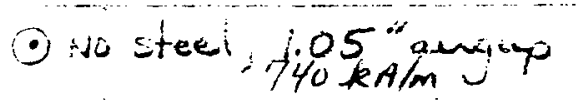
Dsteel, 0.8 "angp $740 \mathrm{kAlm}$ + no stect, $0.55 "$ argip, 7\%okilm $x_{-}=$Lick, at

$$
(\text { for-16) } 7 \text { stace, } 640 \mathrm{jaim}, 0.5=\text { tiregap }
$$

\section{RPAA REQT} +.........

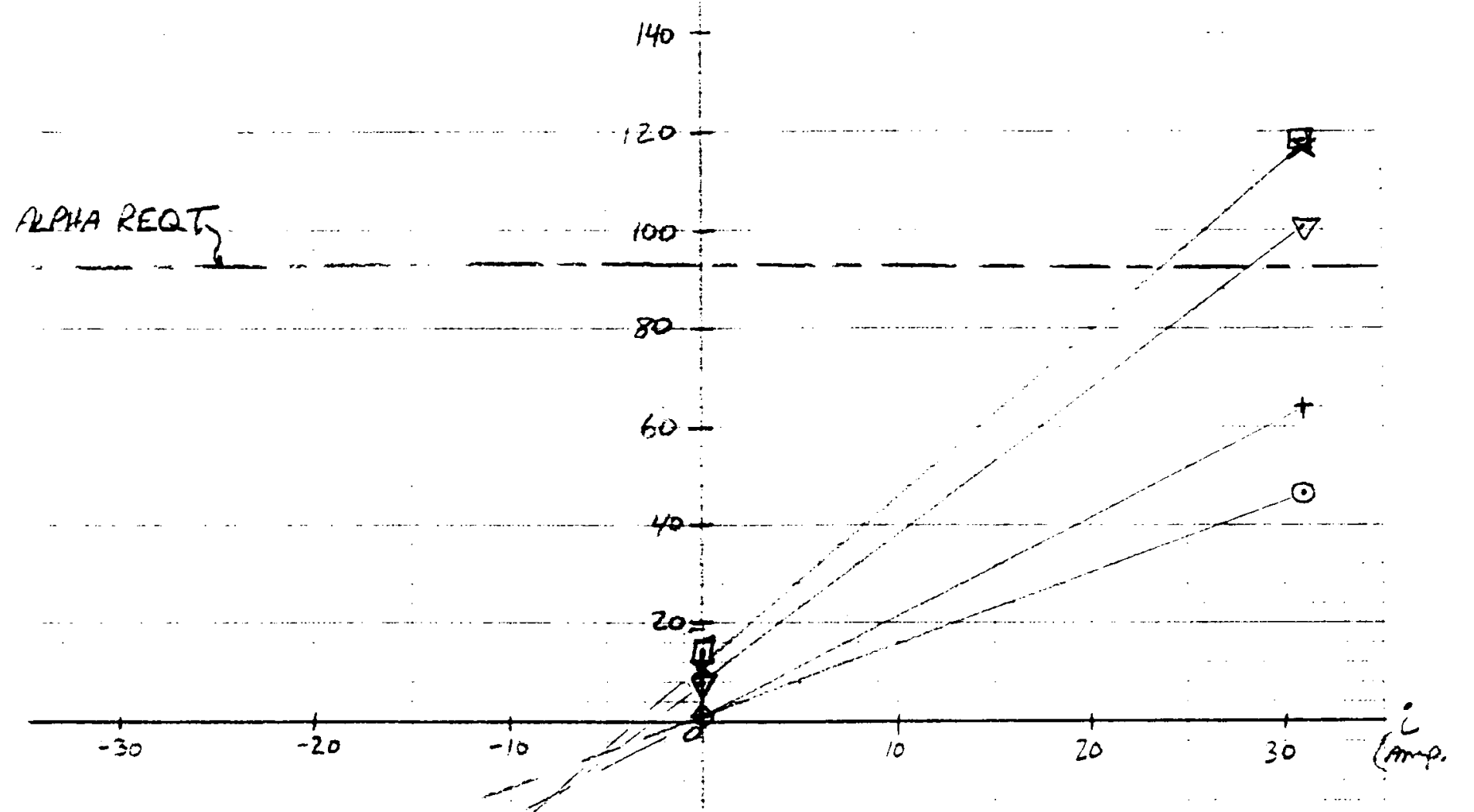

$$
740 \mathrm{kath}
$$

ALPHA

REQT.'
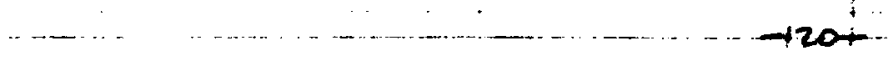

$-140$

Fig. 9. Torque-vs - Current Plots-Showing-Effects- of-Magnet Strength, Air Gap Dimension, and Presence of Steel. 


\section{ALPHA Motor Weight Estimates}

1. With Silicon Steel Tape.

A. Rotor

\begin{tabular}{llllc}
\cline { 1 - 1 } \multicolumn{1}{c}{ Material } & Volume (in. ${ }^{3}$ ) & & Density & Weight (lb) \\
\cline { 5 - 5 } & & & & \\
Back iron ring & 29 & & $7.8 \mathrm{~kg} / \mathrm{dm}^{3}$ & 8.2 \\
G-10 plastic & 72.5 & $1.82 \mathrm{~g} / \mathrm{cm}^{3}$ & 4.8 \\
Magnets & 12 & $7.5 \mathrm{~g} / \mathrm{cm}^{3}$ & $\frac{3.2}{16.2} \mathrm{lb}$
\end{tabular}

Since there are two rotors per module, the total weight for the rotors is estimated to be $32.4 \mathrm{lb}$.

B. Stator

The stator weight is estimated based on a stator thickness of 0.5 in. and total diameter of 17.0 in. A 2-in. hole in the center of the stator is permitted. The weight estimate may be obtained by considering the following parameters for an existing stator:

$\begin{array}{ll}\text { Diameter } & 15 \mathrm{in} . \\ \text { Center hole } & 2 \mathrm{in} . \text { diam } \\ \text { Weight with yoke } & 42 \mathrm{lb}\end{array}$

Since the ALPHA motor stator requires no yoke, an estimate of the weight of an existing stator without the yoke is made:

$\begin{array}{ll}\text { Volume of yoke } & 59 \mathrm{in.}^{3} \\ \text { Density of silicon steel } & 0.276 \mathrm{lb} / \mathrm{in}^{3} \\ \text { Total yoke weight } & 16.4 \mathrm{lb} \\ \text { Stator weight without yoke }= & 25.6 \mathrm{lb}\end{array}$

Since the swept volume of this stator would now be 85 in. $^{3}$ (tooth length $=$ 0.52 in.), the typical density of a random-wound, axial-gap stator with silicon steel teeth (but no yoke) and epoxy-filled slots is $0.3 \mathrm{lb} / \mathrm{in}^{3}$.

The ALPHA motor swept volume is 254 in. $^{3}$. Therefore, the ALPHA motor stator weight would be $32 \mathrm{lb}$.

C. The total estimated motor weight for the motor that delivers $118 \mathrm{ft}-\mathrm{lb}$ of torque at speeds to $700 \mathrm{rpm}$ is

$\begin{array}{ll}2 \text { rotors } & 32.4 \\ \text { stator } & \frac{32 \mathrm{lb}}{64.4 \mathrm{lb}}\end{array}$


Two modules, comprising the complete counterrotating shaft system, would therefore weigh $128.8 \mathrm{lb}$. Since the motor torque exceeds the requirement by

$$
\frac{118 \mathrm{ft}-\mathrm{lb}}{92 \mathrm{ft}-\mathrm{lb}}-1 \times 100 \%=28 \%
$$

The motor geometry may be adjusted to reduce the torque output and meet the weight goal of $120 \mathrm{lb}$ for the motor.

D. The above weight estimates exclude added weight due to

Cooling coils and coolant

Housing

Brush and slip rings

Brush and commutator rings

Shaft and bearings

Bearing lubricants

The only significant item in the above list is the potential weight of the drive shaft; however, innovative materials may be used to keep the weight impact of the shaft, housing, and cooling coils to a minimum.

II. Option of No Steel in Stator Assembly.

Calculations indicate that the motor may deliver about $70 \%$ of its rated, steady-state torque $(64 \mathrm{ft}-\mathrm{lb})$ without the use of steel laminations in the stator. The expected weight reduction in a single stator may be calculated as follows:

Total volume of slots $=21 \times 3$ in. $\times 0.7$ in. $\times 0.5$ in.

$$
=22.05 \text { in. }^{3}
$$

Volume of teeth $=\pi\left[(7)^{2}-(4)^{2}\right]-22.05$ in. $^{3}$

$$
=29.8 \text { in. }^{3}
$$

Therefore, the weight of the teeth no longer needed is

$$
29.8 \text { in. }^{3} \times 0.276 \frac{\mathrm{lb}}{\text { in. }^{3}}=8.2 \mathrm{lb}
$$

Hence, if the stator teeth are removed, the total weight of a motor module would decrease by $13 \%$, but the torque would decrease by $30 \%$. 


\section{Commercial Basis for Confidence in Weight Estimate}

At least one commercial firm ${ }^{2}$ sells a brushless DC "pancake" servo motor that delivers $96 \mathrm{ft}-\mathrm{lb}$ continuous torque at speeds up to $60 \mathrm{rpm}$. The motor assembly weighs $64 \mathrm{lb}$. While the application is much different from the ALPHA project, the availability of such a motor suggests that the use of rare-earth permanent magnets, with $\mathrm{H}_{\mathrm{c}}>700 \mathrm{kA} / \mathrm{m}$, will result in performance meeting or exceeding the present requirement.

\section{Conclusion}

1. The close agreement between the theoretical study in the section "design parameters" and the results of the finite element analysis gives us confidence in the practicality of meeting the desired goal of $700 \mathrm{rpm}$ and $92 \mathrm{ft}$-lb within the ALPHA weight and volume specifications.

2. ALPHA torque specifications will be substantially exceeded through the use of high strength SmCo or NdFeB rare-earth permanent magnets. These magnets allow the designer to adjust motor geometry and/or windings to meet weight, volume, and cooling system limitations.

3. A most attractive option is that of removing all magnetic material from the stator and increasing the number of ampere-turns to meet ALPHA requirements in a more powerdense package.

4. Although the slip ring/commutator and brush system is innovative, the requirements for these components appear to be well within the state-of-the-art.

\footnotetext{
${ }^{2}$ Yokogawa Corp. of America c/o Tech. Tran. Consultants, Inc. Lake Geneva, Wisconsin 53147
} 
